\title{
Synthesis of Ditopic Porphyrins and Lanthanide Complexes on their Basis: Luminescent Features
}

\author{
Nikolay N. Semenishyn, Natalya V. Rusakova, Alexander V. Mazepa, and \\ Yuriy V. Korovin ${ }^{\circledR}$
}

\author{
A. V. Bogatsky Physico-Chemical Institute, Odessa, 65080, Ukraine \\ ${ }^{\circledR}$ Corresponding author E-mail: lanthachem@te.net.ua
}

\begin{abstract}
In this work we describe the synthesis of porphyrins modified with aminopolycarbonic acids - EDTA and DTPA. Several of mono- and homobinuclear ytterbium and lutetium complexes on the basis of ditopic ligands were synthesized. The dependence of 4f-luminescence quantum yield from the structure of complexes is discussed.
\end{abstract}

Keywords: Porphyrin, mono- and homonuclear lanthanide complexes, ditopic ligands, $4 f$-luminescence.

\section{Introduction}

It is known that lanthanide-porphyrins have some advantages in comparison with free-base porphyrins as potential agents in medical practice due to their unique luminescent and magnetic features. ${ }^{[1,2]}$ But their application is confined by two important aspects, such as relatively low chemical stability in comparison with many other metal-porphyrins and negligible value of IR-luminescence quantum yield. In this connection the creation of new stable lanthanide-porphyrins on the basis of porphyrins modified with strong chelating agents has an important role. These objects should exclude the disadvantages of lanthanide-porphyrins. One of the basic priorities in the creation of such compounds is their simultaneous use as the contrast agents in magnetic resonance investigation (MRI) and as the agents in photodynamic therapy (PDT). ${ }^{[3]}$

The modification of porphyrin by the second coordinating ligand, in particular, by aminopolycarbonic acid (e.g. EDTA - ethylenediaminetetraacetic acid or DTPA - diethylenetriaminepentaacetic acid) can be considered as an effective method. But there are only few works which are devoted to such compounds and they don't describe the luminescent properties of lanthanides in them. ${ }^{[3-7]}$ Therefore study of $4 f$-luminescence in these compounds is actual.

In this work the study of the influence of the structure of mono- and homobinuclear lanthanide complexes on their spectral-luminescent properties is carried out. The compounds have been obtained on the basis of ATPP (mono- $p$-aminotetraphenylporphyrin) modified by EDTA and DTPA.

\section{Experimental}

UV-vis spectra were recorded on a Specord M40 UV/VIS (Carl Zeiss, Jena, Germany) and Lambda 9 UV/VIS/NIR (PerkinElmer) spectrometers. Elemental analysis was performed on a Perkin-Elmer Model 240C elemental analyser. ${ }^{1} \mathrm{H}$ NMR spectra were recorded on Bruker Avance-300 (300 MHz) in $\mathrm{CDCl}_{3}$ and DMSO. Mass spectra FAB were recorded on a Varian MAT CH112 spectrometer (Varian BV, Middelburg) using $m$-nitrobenzyl alcohol as the matrix. Emission and excitation spectra were taken on a SDL-2 spectrofluorimeter equipped with a photon counting system and attachment for phosphorescence measurements and spectrofluorimeter Fluorat-02-Panorama (Optic-Mechanical Association - Lumex, St.-Petersburg, Russia). All luminescence spectra were corrected with a standard lamp. A xenon lamp (Xe$150)$ and Nd:YAG laser used as the excitation sources. The relative quantum yields of $4 f$-luminescence $(\varphi)$ for the ytterbium complexes were calculated using Zn-tetraphenylporphyrin as a standard $(\varphi=$ $\left.0.0315^{[8]}\right)$. All luminescent measurements were carried out in DMF at room temperature $\left(25^{\circ} \mathrm{C}\right)$.

Ytterbium and lutetium oxides (99.99\%) were purchased from Aldrich (Gillingham, Dorset). All other chemicals were analytically pure in quality. Synthesis of ATPP, ${ }^{[9,}{ }^{10]} \mathrm{Yb}-\mathrm{ATPP},{ }^{[11]} \mathrm{Yb}-\mathrm{EDTA}$ and Yb-DTPA ${ }^{[12]}$ were realized according to the known methods. The purity of prepared compounds was controlled by ${ }^{1} \mathrm{H}$ NMR, mass spectroscopy and TLC.

((2-\{[2-(Bis-carboxymethyl-amino)-ethyl]-carboxymethylamino $\}$-ethyl)-\{[4-(10,15,20-triphenyl-porphyrin-5-yl)phenylcarbamoyl]-methyl\}-amino)-acetic acid, [ATPP-DTPA]. Synthesis of [ATPP-DTPA] was performed ${ }^{[4]}$ by coupling of equimolar $\left(2 \cdot 10^{-4} \mathrm{~mol}\right)$ quantities of ATPP $(125.5 \mathrm{mg})$ and DTPA dianhydride $(70 \mathrm{mg})$ in dry DMF (20 ml) and $0.1 \mathrm{ml}$ of triethylamine with stirring in nitrogen atmosphere $\left(70^{\circ} \mathrm{C}\right)$. The reaction was continued for 30 - 40 min with TLC monitoring. Obtained crude product was precipitated with water, and then was isolated by column chromatography using silica gel (100-150 mesh) as the adsorbent and a mixture of $\mathrm{CHCl}_{3} /$ methanol as the eluent. Yield $0.12 \mathrm{~g}(60 \%)$, m.p. $>300^{\circ} \mathrm{C}$ (decomposed). Found: C 68.96, H 5.31 \%. $\mathrm{C}_{58} \mathrm{H}_{52} \mathrm{~N}_{8} \mathrm{O}_{9}$ requires $\mathrm{C} 69.17, \mathrm{H}$ 5.40. UV-vis $\lambda_{\text {max }}$ (DMF) nm (lge): 419 (5.65), 515 (4.30), 550 (4.11), 592 (3.94), 647 (3.96). $\delta_{\mathrm{H}}\left(\left[D_{6}\right] \mathrm{DMSO}, 300 \mathrm{~K}\right)-2.93(2 \mathrm{H}, \mathrm{s}$, pyrrole-NH), $10.6(4 \mathrm{H}, \mathrm{s}$, $\mathrm{COOH}), 7.84(11 \mathrm{H}, \mathrm{b}, \mathrm{Ph}), 8.22(8 \mathrm{H}, \mathrm{b}, \mathrm{Ph}), 3.15-3.8(18 \mathrm{H}, \mathrm{b}$, - $\left.\mathrm{CH}_{2}-\right), 6.70(1 \mathrm{H}, \mathrm{s},-\mathrm{CONH}-), 8.83(8 \mathrm{H}, \mathrm{s}$, pyrrole-H). $m / z$ (FAB) (\%) $1005(10)\left[(\mathrm{M}+\mathrm{H})^{+}\right]$.

\{Carboxymethyl-[2-(carboxymethyl-\{[4-(10,15,20-triphenylporphyrin-5-yl)-phenylcarbamoyl]-methyl\}-amino)-ethyl]-amino\}acetic acid, [ATPP-EDTA]. Synthesis of [ATPP-EDTA] was performed by the same method with one difference: instead of DTPA dianhydride, EDTA dianhydride (52 mg) was used. Yield $0.11 \mathrm{~g}(63 \%)$, m.p. $>300^{\circ} \mathrm{C}$ (decomposed). Found: C 71.46, H $5.18 \%$. $\mathrm{C}_{54} \mathrm{H}_{45} \mathrm{~N}_{7} \mathrm{O}_{7}$ requires C 71.75, H 5.02. UV-vis $\lambda_{\max }$ (DMF) nm (lge): 419 (5.63), 515 (4.31), 550 (4.11), 592 (3.95), 647 (3.96). $\delta_{\mathrm{H}} \mathrm{CDCl}_{3}$, $300 \mathrm{~K})-2.93(2 \mathrm{H}$, s, pyrrole-NH), $10.6(3 \mathrm{H}, \mathrm{s}, \mathrm{COOH}), 7.77(11 \mathrm{H}, \mathrm{b}$, $\mathrm{Ph}), 8.21$ (8H, b, Ph), 3.3-4.1 (12H, b, - $\left.\mathrm{CH}_{2}-\right)$, 6.70 (1H, s, -CONH-), $8.84\left(8 \mathrm{H}, \mathrm{s}\right.$, pyrrole-H). $m / z$ (FAB) (\%) 904 (18) [(M+H) $\left.{ }^{+}\right]$. 
General procedure for synthesis of mononuclear complexes on the base of ditopic ligands, [ATPP-DTPA-Ln] and [ATPP-EDTA$L n$ ], $L n=Y b, L u$. Synthesis of [ATPP-DTPA-Ln] [ATPP-EDTA-Ln] was carried out by interaction of $2 \cdot 10^{-4} \mathrm{~mol}$ [ATPP-DTPA] [ATPPEDTA] with 3 drops of $\mathrm{LnCl}_{3}$ aq. in DMF (20 ml). After stirring (50 ${ }^{\circ} \mathrm{C}$ ) during $10 \mathrm{~min}$ the crude product was precipitated with water, filtered and recrystallized.

$[A T P P-D T P A-Y b]$. Yield 0.22 g (95\%), m.p. $>300^{\circ} \mathrm{C}$ (decomposed). Found: $\mathrm{C} 58.83, \mathrm{H} 4.41, \mathrm{Yb} 15.03 \% . \mathrm{C}_{58} \mathrm{H}_{51} \mathrm{~N}_{8} \mathrm{O}_{9} \mathrm{Yb}$ requires $\mathrm{C} 59.08, \mathrm{H} 4.53, \mathrm{Yb}$ 14.67. $\lambda_{\max }$ (DMF) nm (lge): 419 (5.56), 515 (4.36), 550 (4.18), 591 (4.05), 647 (4.04). $\mathrm{m} / \mathrm{z}$ (FAB) (\%) $1175(13)\left[(\mathrm{M}+\mathrm{H})^{+}\right]$.

[ATPP-DTPA-Lu]. Yield 0.22 g (95\%), m.p. $>300^{\circ} \mathrm{C}$ (decomposed). Found: C 58.90, H 4.63, $\mathrm{Lu} 14.45 \% . \mathrm{C}_{58} \mathrm{H}_{51} \mathrm{~N}_{8} \mathrm{O}_{9} \mathrm{Lu}$ requires $\mathrm{C} 58.98, \mathrm{H} 4.52$, $\mathrm{Lu} 14.81 . \lambda_{\text {max }}$ (DMF) $\mathrm{nm}(\lg \varepsilon): 419$ (5.56), 515 (4.36), 550 (4.18), 591 (4.05), 647 (4.04). $\delta_{\mathrm{H}}\left(\mathrm{CDCl}_{3}, 300 \mathrm{~K}\right)$ $-2.93(2 \mathrm{H}, \mathrm{s}$, pyrrole- $\mathrm{NH}), 10.52(1 \mathrm{H}, \mathrm{s}, \mathrm{COOH}), 7.75(11 \mathrm{H}, \mathrm{b}, \mathrm{Ph})$, 8.20 (8H, b, Ph), 3.5-3.7 (18H, b, - $\left.\mathrm{CH}_{2}-\right), 6.69$ (1H, s, -CONH-), 8.82 (8H, s, pyrrole-H). $m / z$ (FAB) (\%) 1176 (13) [(M+H) $\left.{ }^{+}\right]$.

$[A T P P-E D T A-Y b]$. Yield $0.20 \mathrm{~g}(95 \%)$, m.p. $>300^{\circ} \mathrm{C}$ (decomposed). Found: $\mathrm{C} 60.06, \mathrm{H} 4.09, \mathrm{Yb} 15.77 \% . \mathrm{C}_{54} \mathrm{H}_{42} \mathrm{~N}_{7} \mathrm{O}_{7} \mathrm{Yb}$ requires $\mathrm{C}$ 60.39, H 3.94, $\mathrm{Yb}$ 16.11. $\lambda_{\max }$ (DMF) nm (lge): 419 (5.56), 515 (4.36), 550 (4.18), 591 (4.05), 647 (4.04). $\mathrm{m} / z$ (FAB) (\%) $1075(18)\left[(\mathrm{M}+\mathrm{H})^{+}\right]$.

[ATPP-EDTA-Lu]. Yield 0.20 g (95\%), m.p. $>300^{\circ} \mathrm{C}$ (decomposed). Found: $\mathrm{C} 60.40, \mathrm{H} 4.01, \mathrm{Lu} 16.54 \% . \mathrm{C}_{54} \mathrm{H}_{42} \mathrm{~N}_{7} \mathrm{O}_{7} \mathrm{Lu}$ requires $\mathrm{C} 60.28, \mathrm{H} \mathrm{3.93}, \mathrm{Lu} 16.26 . \lambda_{\max }(\mathrm{DMF}) \mathrm{nm}(\lg \varepsilon): 419$ (5.56), 515 (4.36), 550 (4.18), 591 (4.05), 647 (4.04). $\delta_{\mathrm{H}}\left(\mathrm{CDCl}_{3}\right.$, $300 \mathrm{~K})$-2.93 (2H, s, pyrrole-NH), $7.77(11 \mathrm{H}, \mathrm{b}, \mathrm{Ph}), 8.20(8 \mathrm{H}, \mathrm{b}$, $\mathrm{Ph})$, 3.6-3.9 (12H, b, - $\left.\mathrm{CH}_{2}-\right), 6.69(1 \mathrm{H}, \mathrm{s},-\mathrm{CONH}-), 8.84(8 \mathrm{H}, \mathrm{s}$, pyrrole-H). $m / z$ (FAB) (\%) $1076(16)\left[(\mathrm{M}+\mathrm{H})^{+}\right]$.

General procedure for synthesis of binuclear complexes on the base of ditopic ligands, [ATPP-DTPA-Ln $]$ and [ATPP-EDTA$\left.L n_{2}\right], L n=Y b, L u$.

Syntheses was performed by interaction of [ATPP-DTPA] or [ATPP-EDTA] $\left(2 \cdot 10^{-4} \mathrm{~mol}\right)$ with 20 drops of lanthanide chlorides in mixture of 1,2-dichlorobenzene-DMF (20 ml) during 24 hours. After the reaction completion 1,2-dichlorobenzene was sublimated and then the crude product was precipitated with water, filtered and separated by column chromatography using silicagel as adsorbent. Yield 50\%.

$\left[A T P P-D T P A-Y b_{2}\right] \cdot m / z$ (FAB) (\%) $800(76)[(\mathrm{M}-\mathrm{Yb}-$ DTPA) $)^{+}$. Found: $\mathrm{C} 58.83, \mathrm{H} 4.41, \mathrm{Yb} 15.03 \% \mathrm{C}_{58} \mathrm{H}_{51} \mathrm{~N}_{8} \mathrm{O}_{9} \mathrm{Yb}$ requires $\mathrm{C} 59.08, \mathrm{H} 4.53, \mathrm{Yb} 14.67 . \lambda_{\max }$ (DMF) nm (lge): 426 (5.58), 557 (4.05), 596 (4.04).

[ATPP-DTPA-Lu $]: m / z$ (FAB) (\%) 801 (72) [(M - LuDTPA) ${ }^{+}$. Found: $\mathrm{C} 58.90, \mathrm{H} 4.63, \mathrm{Lu} 14.45 \% . \mathrm{C}_{58} \mathrm{H}_{51} \mathrm{~N}_{8} \mathrm{O}_{9} \mathrm{Lu}$ requires $\mathrm{C} 58.98, \mathrm{H} 4.52, \mathrm{Lu} 14.81 . \delta_{\mathrm{H}}\left(\mathrm{CDCl}_{3}, 300 \mathrm{~K}\right) 10.52$ (s, $1 \mathrm{H}, \mathrm{COOH}), 7.75\left(\mathrm{~b}, 11 \mathrm{H}, p, m-\mathrm{H}_{\mathrm{Ph}}\right), 8.2\left(\mathrm{~b}, 8 \mathrm{H}, o-\mathrm{H}_{\mathrm{Ph}}\right), 8.82$ (s, 8H, pyrrole-H), 3.5-3.7 (b, 18H, - $\mathrm{CH}_{2}$ - of DTPA), 6.69 (s, $1 \mathrm{H}$, -CONH-). $\lambda_{\text {max }}$ (DMF) nm/(lge): 426 (5.59), 557 (4.08), 596 (4.10).

$\left[A T P P-E D T A-Y b_{2}\right] . m / z$ (FAB) (\%) $800(71)$ [(M - YbEDTA $)^{+}$. Found: C 50.22, H 3.78, Yb $27.11 \% . \mathrm{C}_{54} \mathrm{H}_{44} \mathrm{ClN}_{7} \mathrm{O}_{7} \mathrm{Yb}_{2}$ requires C 50.49, H 3.45, Yb 26.94. $\lambda_{\text {max }}$ (DMF) $\mathrm{nm}(\lg \varepsilon) 426(5.50)$, 557 (4.09), 596 (4.04).

[ATPP-EDTA-Lu $]$ ]. m/z (FAB) (\%) 801 (78) [(M - LuEDTA $\left.)^{+}\right] . \delta_{\mathrm{H}}\left(\mathrm{CDCl}_{3}, 300 \mathrm{~K}\right) 7.75\left(\mathrm{~b}, 11 \mathrm{H}, p, m-\mathrm{H}_{\mathrm{Ph}}\right), 8.2(\mathrm{~b}, 8 \mathrm{H}$, $\left.o-\mathrm{H}_{\mathrm{Ph}}\right), 8.82$ (s, 8H, pyrrole-H), 3.6-3.9 (b, 12H, $-\mathrm{CH}_{2}-$ of EDTA), 6.69 (s, 1H, -CONH-). Found: C 50.72, H 3.61, Yb $26.72 \%$. $\mathrm{C}_{54} \mathrm{H}_{44} \mathrm{ClN}_{7} \mathrm{O}_{7} \mathrm{Yb}_{2}$ requires $\mathrm{C} 50.64, \mathrm{H} 3.45, \mathrm{Yb} 26.83 . \lambda_{\text {max }}$ (DMF) nm (lge): 426 (5.52), 557 (4.01), 596 (4.02).

\section{Results and Discussion}

The structures of studied compounds are presented in Figure 1. As it seen from the structure both compounds have two centers of coordination (porphyrinic and aminopolycarbonic). Taking into account the fact that lanthanide-porphyrins are formed only under high temperatures (more than $150{ }^{\circ} \mathrm{C}$ ) in contrast to aminopolycarboxylates of lanthanides such ditopic ligands can selectively form mononuclear and binuclear complexes. It allows to carry out the study of changes in spectralluminescent features of these compounds in dependence of quantity of lanthanide ions in structure.

There are some changes in absorption spectra of ATPP under the modification of porphyrin by EDTA or DTPA fragments. In particular, the increase in absorption intensity as well as hypsochromic shifts $(\Delta \lambda=5-8 \mathrm{~nm})$ of I and III $Q$-bands takes place. At the complexation on aminopolycarboxylic fragment of [ATPP-EDTA] [ATPP-DTPA] the absorption spectra do not change. It proves that porphyrin ring is not complexed whiles at the complexation with f-metals the absorption spectra as a rule become three-banded with batochromically shifted Soret band. When homobinuclear complexes are formed the spectra are undergone standard changes the same to "classic" lanthanide-porphyrins.

It is known that $4 f$-luminescence (Figure 2) in complexes with porphyrins is observed only for $\mathrm{Yb}^{3+}, \mathrm{Nd}^{3+}$ and $\mathrm{Er}^{3+}$ ions. ${ }^{[13]}$ It is dealt with low location of triplet levels of porphyrins $\left(E_{\mathrm{T}} \approx 12000-15000 \mathrm{~cm}^{-1}\right)$. Energy transfer to resonance levels of these ions is possible $(10200,11500$, $6450 \mathrm{~cm}^{-1}$, respectively) from porphyrin levels.

The coincidence between the absorption and excitation spectra of the complexes clearly shows that the ligand-tolanthanide ion energy transfer from the triplet levels of porphyrins to the resonance ${ }^{2} \mathrm{~F}_{5 / 2}$-level of $\mathrm{Yb}^{3+}$ takes place.

We have established that the monosubstitution on porphyrin fragment in one carboxylic group (DTPA and EDTA) leads to the sharp increasing (Table 1) in quantum yield of 4 -luminescence ( $\varphi=1.5 \cdot 10^{-3}$ and $1.1 \cdot 10^{-3}$ accordingly) as compared to [Yb-DTPA] and [Yb-EDTA] (it is impossible to measure the exact values of quantum yields for these compounds because they are very low). It is apparently resulting from excitation energy transfer through the "antenna-effect". In the case of [ATPP-DTPA-Yb] the quantum yield is higher than in the case of [ATPP-EDTA-Yb]. This phenomenon is realized owing to more shield effect of DTPA-fragment in comparison with EDTA-fragment that consists in shielding of $\mathrm{Yb}^{3+}$ from different factors which result in quenching of $4 f$-luminescence. One of these factors is oscillation of $\mathrm{C}-\mathrm{H}$ and $\mathrm{O}-\mathrm{H}$ bonds of solvent molecules that absorb the light in the range of $4 f$-luminescence of $\mathrm{Yb}^{3+}$ ions.

For elucidate the degree of quenching process by different metals also we have investigated the molecular luminescence of ligands (maxima at 654 and $715 \mathrm{~nm}$ ) and corresponding complexes. In the investigated mononuclear lanthanide complexes the essential quenching of luminescence by lanthanide ions was not established. However, $40 \%$-quenching of luminescence by copper ions included into aminopolycarbonic ATPP-DTPA fragment was established. It is important because the possibility of interaction of porphyrin and metal ion in aminopolycarbonic fragment can be realized (despite the fact that complexation on EDTA or DTPA fragment not influence on absorption spectra). These data indicate that energy transfer from porphyrin to $\mathrm{Yb}^{3+}$ ion is partial. Therefore the quantum yields of $4 f$-luminescence for mononuclear complexes on the 
base of ditopic ligands are less in comparison with "classic" lanthanide-porphyrins, e.g. [Yb-ATPP(Cl)].

We have obtained the analogous dependence for homobinuclear complexes on the base of [ATPP-EDTA] and [ATPP-DTPA]. But in these compounds values of quantum yield are higher $\left(2.8 \cdot 10^{-3}\right.$ and $3.2 \cdot 10^{-3}$ accordingly) in comparison with mononuclear complexes. It can be explained by more effective energy transfer from porphyrin to $\mathrm{Yb}^{3+}$ ions. Moreover, in these complexes the molecular luminescence is completely quenched like in "classic" lanthanide-porphyrins. Values for both homobinuclear complexes are higher than for [Yb-ATPP(Cl)], probably due to more effective excitation energy transfer between two ions of ytterbium.
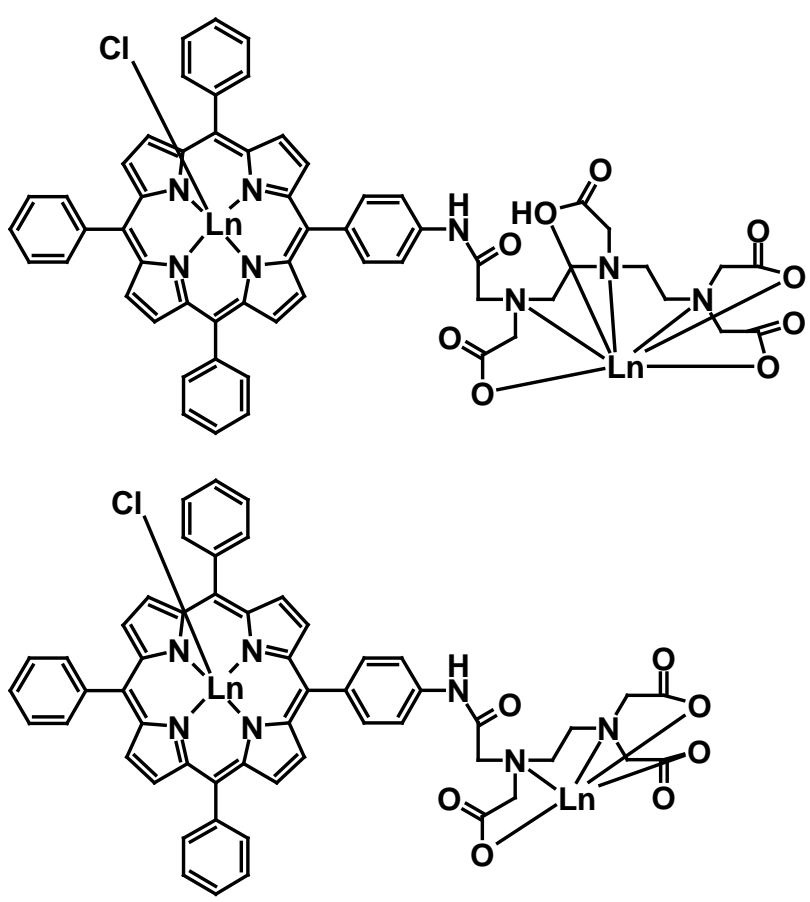

Figure 1. Structures of complexes studied $\mathrm{Ln}=3 \mathrm{H}, \mathrm{Yb}, \mathrm{Lu}, \mathrm{LnCl}$ $=2 \mathrm{H}, \mathrm{YbCl}, \mathrm{LuCl}$.

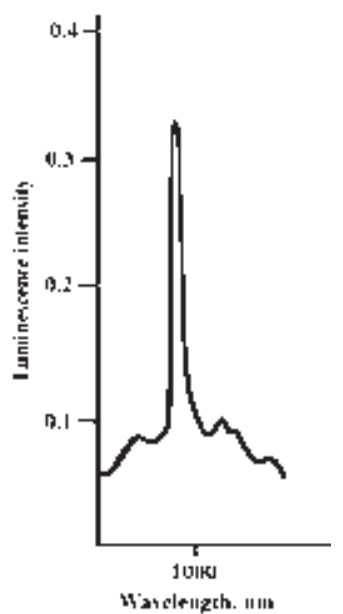

Figure 2. 4f-Luminescence spectrum of $\mathrm{Yb}^{3+}$ ion in studied compounds.
Table 1. 4f-Luminescence quantum yield of $\mathrm{Yb}^{3+}$ ion in complexes studied. Error is $\pm 10 \%$ (solutions in DMF, $\mathrm{C}=10^{-6} \mathrm{M}$ ).

\begin{tabular}{lc}
\hline Compound & $\varphi \times 10^{3}$ \\
\hline Yb-EDTA & - \\
Yb-DTPA & - \\
ATPP-EDTA-Yb & 1.1 \\
ATPP-DTPA-Yb & 1.4 \\
ATPP-EDTA-Yb $(\mathrm{Cl})$ & 2.8 \\
ATPP-DTPA- $\mathrm{Yb}_{2}(\mathrm{Cl})$ & 3.2 \\
Yb-ATPP(Cl) & 2.0 \\
\hline
\end{tabular}

\section{Conclusions}

We have synthesized new ditopic ligands on the base of mono- $p$-aminotetraphenylporphyrin, as well as corresponding mono- and homobinuclear lanthanide-containing complexes. It has been found that values of $4 f$-luminescence quantum yield for the same complexes on the base of [ATPP-DTPA] are higher than for [ATPP-EDTA]. Homobinuclear complexes have more effective $4 f$-luminescence than mononuclear complexes.

Acknowledgements. The presented work was supported by the Scientific Grant No. 14.3/002 from "Fundamental Researches Joint Projects Competition, BRFFI - UFFI Program”.

\section{References}

1. Gaiduk M.I., Grigoryants V.V., Mironov A.F., Roytman L.D., Chissov V.I., Rumyantseva V.D., Sukhin G.M. Dokl. AN SSSR 1989, 309, 980-983.

2. Richard E. P. Winpenny. Chem. Soc. Rev. 1998, 27, 447-452.

3. Li G., Slansky A., Dobhal M.P., Goswami L.N., Graham A., Chen Y., Kanter P., Alberico R.A., Spernyak J., Morgan J., Mazurchuk R., Oseroff A., Grossman Z., Pandey R.K. Bioconjugate Chem. 2005, 16, 32-42.

4. Shin K., Yeu D.H. J. Korean Chem. Soc. 1999, 43, 611-613.

5. Yicheng Ni, Marchal G., Jie Yu, Lukito G., Petre C., Wevers M., Baert A.L., Ebert W., Hilger C.S., Maier F.K., Semmler W. Acad. Radiol. 1995, 2, 687-699.

6. Hofmann B., Bogdanov A., Marecos E., Ebert W., Semmler W., Weissleder R. J. Magn. Reson. Imaging 1999, 9, 336-341.

7. Hindre F., Plouzennec M., Certaines J., Foultier M.T., Thierry P., Simonneaux G. J. Magn. Reson. Imaging 1993, 3, 59-65.

8. Shushkevich I.K., Dvornikov S.S., Kachura T.F., Solov'ev K. N. J. Appl. Spectr. 1981, 35, 1109-1113.

9. Luguya R., Jaquinod L., Fronczek F.R., Vicente M., Smith K. Tetrahedron 2004, 60, 2757-2763.

10. Kruper W., Chamberlin T., Kochanny M. J. Org. Chem. 1989, 54, 2753-2756.

11. Spyroulias G.A., Despotopoulos A.P., Raptopoulou C.P., Terzis A., Montauzon D., Poilblanc R., Coutsolelos A.G. Inorg. Chem. 2002, 41, 2648-2659.

12. Inomata Y., Sunakawa T., Howell F. S. J. Mol. Struct. 2003, 648, 81-88.

13. Tsvirko M.P., Stelmakh G.F., Pyatosin V.E., Solovyov K.N., Kachura T.F., Piskarskas A.S., Gadonas R.A. Chem. Phys. 1986, 106, 467-476. 